terapia periodontal tem como objetivo restaurar a inserção periodontal nomeadamente do osso alveolar, ligamento periodontal e cemento perdidos por trauma ou patologia. Com a cirurgia periodontal plástica pretende-se recuperar a integridade dos tecidos bem como a harmonia estética do sorriso.

Descrição do caso clínico: Paciente do sexo feminino, 27 anos, ASA I, não fumadora e com várias lesões causadas por trauma de escovagem. Como diagnóstico periodontal apresentava gengivite induzida por placa com um índice de placa de $87,03 \%$ e índice de sangramento de $8,02 \%$. A sua principal queixa era a estética associada à recessão na face vestibular do dente 43, classe I de Miller. A primeira linha de tratamento inclui a remoção de fatores etiológicos seguida de correção cirúrgica com a técnica vestibular incision subperiosteal tunnel acess (VISTA). Foi feito o aplanamento das raízes e o seu condicionamento com tetraciclinas ao qual se seguiu uma incisão para acesso vestibular na zona do dente 43 e a elevação de um túnel subperiósteo entre o periósteo e o osso. No palato duro foi feita uma incisão para se obter um enxerto gengival livre que foi posteriormente desepitelizado. Por fim, o retalho e o complexo mucogengival foram avançados e estabilizados por sutura na sua nova posição, coronalmente à linha amelocementaria, de forma a ser feito o recobrimento radicular. Posteriormente, foram realizados pontos ancorados na férula da paciente. 10 dias após a cirurgia foi feita a remoção dos pontos e a paciente não reportou dor ao nível da zona do dente 43, apenas sentia desconforto no palato quando tirava a proteção.

Discussão e conclusões: A técnica VISTA é simples e rápida sendo bastante eficaz no reposicionamento coronal da margem gengival quando comparada com outras técnicas. A incisão diminui a possibilidade de trauma gengival e as cicatrizes são pouco visíveis. A paciente apresentava uma recessão de $1 \mathrm{~mm}$, que após a conclusão do tratamento conseguiu-se um recobrimento total da mesma, sem sintomatologia associada. Têm sido feitos controlos periódicos aos 3 meses e de momento aos 6 meses e verifica-se uma completa resolução da recessão gengival na zona do dente 23 . http://doi.org/10.24873/j.rpemd.2018.11.312

\section{\#076 Simplificar o registo da Relação Cêntrica com o Arco Gótico}

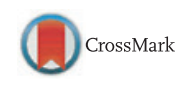

Ana Ribeiro*, Mariana Capelas, António Capelas, Américo Ribeiro, Margarida Sampaio Fernandes, Maria Helena Figueiral

\section{FMDUP}

Introdução: A confeção de próteses totais envolve a procura de condições ótimas de estética, função e fonética, muitas vezes difíceis de conseguir. Para isto, é necessário ter em conta os determinantes de oclusão nomeadamente a correta relação maxilo-mandibular, o que implica ter competências técnicas para estabelecer a dimensão vertical de oclusão e a relação cêntrica de forma que sejam reproduzíveis e verificáveis. A determinação da relação cêntrica e da dimensão vertical de oclusão torna-se difícil em especial em pacientes idosos, com perda da coordenação muscular e portadores de próteses antigas. A relação vertical adequada depende da consideração de vários fatores incluindo tónus muscular, espaço disponível entre arcadas e paralelismo das cristas alveolares. O traçado do arco gótico consiste num mecanismo de determinação da relação cêntrica após determinação da dimensão vertical no qual o paciente realiza movimentos funcionais como a lateralidade, protrusão e retrusão. O ponto de partida destes movimentos será visualizado como o ponto de encontro do traçado e representa a relação cêntrica.

Descrição do caso clínico: Paciente, 62 anos, género masculino, compareceu na consulta da Faculdade de Medicina Dentária da Universidade do Porto com o propósito de confecionar novas próteses totais removíveis superior e inferior. Apresentava próteses totais desadaptadas e com oclusão desajustada. Na anamnese, referiu cirurgia há 2 meses de exérese de hiperplasia fibroepitelial por trauma associado ao uso das próteses. Encaminhado para a Clínica de Outono da Faculdade, foi iniciado o estudo e planeamento para confeção destas próteses. A posição mandibular escolhida para a reabilitação oral foi a relação cêntrica, pelo que optamos pelo uso do arco gótico.

Discussão e conclusões: O traçado do arco gótico é um método eficaz e prático na obtenção de posições mandibulares em movimento numa relação cêntrica e dimensão vertical de oclusão adequadas. A determinação e registo da relação cêntrica e da dimensão vertical nos pacientes desdentados totais por vezes não é fácil de conseguir, pelo que está indicada a combinação de vários procedimentos para facilitar a sua correta obtenção. Nestes casos a utilização do arco gótico pode ser uma mais valia, sendo que o dentista deve possuir conhecimento suficiente das técnicas a utilizar.

http://doi.org/10.24873/j.rpemd.2018.11.313

\section{\#077 O polimorfismo da IL1 na patogenia de complicações implantares - um caso clínico}

Ricardo Batista*, André Moreira, Margarida Sampaio Fernandes, Pedro Ferrás, Paula Vaz, MH Figueiral

Faculdade de Medicina Dentária da Universidade do Porto

Introdução: Entre os diversos fatores de risco para a doença peri-implantar, a resposta imunitária do hospedeiro e a colonização bacteriana possuem um papel fulcral na patogenia. O teste genético para periodontite $\left(\mathrm{TGP}^{\circledR}\right)$ permite a identificação de dois polimorfismos genéticos da IL1 associados à doença. O objetivo deste trabalho é demonstrar o potencial interesse da realização do teste $\mathrm{TGP}^{\circledR}$ na prática clínica, em casos de complicações implantares recorrentes.

Descrição do caso clínico: Paciente Caucasiano, género masculino, 65 anos de idade, não fumador e sem patologia sistémica, com história de perda de três implantes de uma prótese fixa mandibular sobre 6 implantes e reabilitação posterior com prótese removível sobre dois pilares Locator ${ }^{\circledR}$, compareceu na consulta do CERO da FMDUP. Apresentou como queixa mau estar à mastigação, observando-se, em exame clínico, presença de sinais inflamatórios (edema, eritema) e acumulação de placa bacteriana peri-implantar. O exame imagiológico evidenciou perda óssea associada. Realizou-se um teste genético TGP ${ }^{\circledR}$, com recolha de material biológico através de zaragatoa bucal, que se revelou positivo. Perante a situação clínica, decidiu-se realizar exérese do tecido infetado peri-implantar e rebasamento da sobredentadura com condicionador de tecidos. 
Discussão e conclusões: Têm sido sugeridas diferentes abordagens de descontaminação peri-implantar, incluindo métodos mecânicos, químicos, laser, entre outros. Neste caso clínico, perante o genótipo positivo para a IL-1 e história prévia de perda implantar, optou-se pelo método clássico, de exérese do tecido infetado, sem qualquer tratamento da superfície implantar. É determinante a consciencialização do paciente sobre a presença de um genótipo positivo, no que diz respeito ao risco de recidiva e redução da carga microbiana peri-implantar, sobretudo para o controle do imbalance hospedeiro/microbiota e consequente manutenção da reabilitação oral. A realização do teste genético para polimorfismos da interleucina-1 deve constituir uma ferramenta auxiliar na planificação e previsibilidade da reabilitação oral com implantes dentários.

http://doi.org/10.24873/j.rpemd.2018.11.314

\section{\#078 Facetas IPS e.max maquinadas - Caso clínico com registo laboratorial}

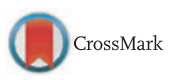

André Moreira*, Ricardo Batista, Margarida Sampaio Fernandes, Susana Oliveira, JC Sampaio Fernandes, MH Figueiral

Faculdade de Medicina Dentária da Universidade do Porto

Introdução: Os sistemas CAD/CAM permitem, a partir dos scans intra ou extra-oral, efetuar o enceramento digital e confecionar restaurações monolíticas para restaurações cerâmicas, nomeadamente facetas em Dissilicato de Lítio. O objetivo do presente trabalho é apresentar e discutir um caso clínico, onde foram realizadas quatro facetas em dissilicato de lítio para os incisivos maxilares.

Descrição do caso clínico: Paciente do sexo feminino, com 41 anos de idade, apresentou-se insatisfeita com a estética das restaurações presentes nos quatro incisivos maxilares (antigas, escurecidas e desadaptadas). Após exame clínico, foi realizado o mock-up direto, decidindo-se, juntamente com a paciente, a proporção e a forma das futuras restaurações. Após impressão, em silicone putty, ao mock-up, efetuaram-se as preparações dentarias, utilizando como guia o mock-up. De seguida, alteraram-se a cor dos cotos, para equilibrar o substrato, antes de serem realizadas impressões em silicone e confeção dos provisórios. Em laboratório o modelo digital foi trabalhado para fresar blocos de $\mathrm{CAD} \mathrm{EMAX}^{\circledR}$. Através do try-in, cada restauração foi testada, com diferentes cores do cimento resina não-adesivo fluído, de elevada carga - Clearfil ${ }^{\circledR}$ Majesty ESFlow (Kuraray Noritake ${ }^{\circledR}$ ). Passou-se à a colagem com o cimento da cor selecionada.

Discussão e conclusões: O presente trabalho discute uma abordagem conservativa e previsível da reabilitação de restaurações antigas, de grandes dimensões. Ao contrário do método tradicional, é possível concluir-se o plano de tratamento numa única visita, desde que se possua sistema de CAM no consultório. Mais ainda, é fácil aproximar as facetas cerâmicas definitivas das provisórias. No entanto, as facetas em Dissilicato de Lítio, confecionadas pelo sistema CAD/CAM, são restaurações monolíticas, onde obtemos a forma final mas sem translucidez no bordo e outras caracterizações. Alguns estudos reportam taxas de sucesso de $95 \%$, ao fim de 5 anos e de $85 \%$, ao fim de 10 anos, embora sejam comumente reportados problemas de descolagem, fratura, manchas e infiltrações. Todas as restaurações fa- bricadas encontraram-se aceitáveis, em termos de adaptação marginal, forma, contorno e estética. O CAD permite ao clínico e laboratório alterarem o protótipo final, para alcançar as expectativas do paciente, quando, e se, necessário. O CAM permite realizar todo o plano de tratamento numa única sessão clínica. http://doi.org/10.24873/j.rpemd.2018.11.315

\section{INVESTIGAÇÃO ORIGINAL}

\section{\#079 Estudo qualitativo da informação \\ clínica de Imunohemoterapia para \\ procedimentos dentários}

Ana Cruz*, José Frias-Bulhosa

FCS-UFP; Departamento de Saúde Pública Oral

- Instituto de Saúde Pública da Univ. Porto

Objetivos: O aumento da esperança de vida conduziu ao aumento da prevalência de doenças crónicas, como as doenças cardiovasculares requerendo na maioria das vezes, terapêutica antitrombótica com anticoagulantes orais. Dado que na maioria dos casos será um tratamento crónico sendo espectável que estes pacientes possam vir a necessitar de procedimentos estomatológicos. O objetivo foi de caracterizar e analisar a adequação do tipo da informação clínica enviada pelos médicos dentistas ou estomatologistas ao serviço de Imunohemoterapia do hosp. Barcelos e o enquadramento técnico-científico dessas solicitações.

Materiais e métodos: Após aprovação por comissão de ética hospitalar realizou-se estudo transversal qualitativo baseado em amostra de conveniência com 33 voluntários, (61\% feminino) pacientes adultos frequentadores da consulta de Imunohemoterapia, medicados com terapêutica hipocoagulante oral. Desenvolveu-se base de dados para registar e catalogar a informação trocada entre os médicos dentistas/estomatologistas com serviço de Imunohemoterapia e dados constantes do boletim terapêutico da medicação anticoagulante do utente para posteriormente proceder a uma interpretação determinista da informação clínica proveniente da troca de informação. Com recurso ao programa NVivo ${ }^{\circledR}$ v12, foram catalogados e analisados dados qualitativos referente ao tipo e adequação da informação trocada entre o serviço de Imunohematologia e os clínicos e eventual análise de modelos se examine eventuais relações nos dados.

Resultados: O tipo de procedimentos clínicos foram maioritariamente exodontia (88\%), sendo que em $51,5 \%$ dos casos não continha a data do procedimento. Em 42,4\% das solicitações não foi fornecida qualquer informação clínica, em 27,3\% a informação era solicitada oralmente através do paciente, quando esta era fornecida, observa-se a orientação do clínico para intervenções cirúrgicas minor em hipocoagulado que sem enquadramento nas atuais guidelines e tinham origem quer em clínicas dentárias (75,8\%), quer em serviços hospitalares.

Conclusões: Idosos que não sendo portadores de informação escrita e sem cuidador acompanhante necessitam frequentemente de adiamento da intervenção estomatológica, tanto pela ausência de informação, como por informação escassa, errada ou contraditória. Os dados demonstram tendência de desresponsabilização dos clínicos para a tomada de 